
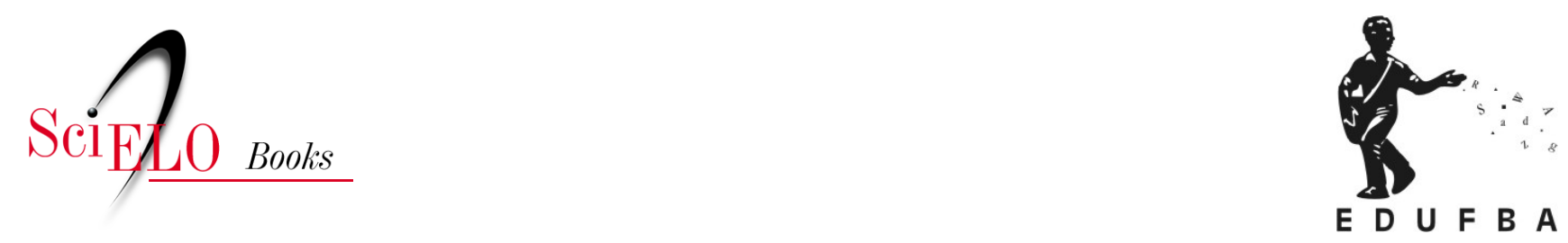

\title{
Policy \\ Educação em saúde bucal do trabalhador
}

\author{
Mariangela Silva de Matos \\ Patrícia Suguri Cristino \\ Tatiana Frederico de Almeida
}

\section{SciELO Books / SciELO Livros / SciELO Libros}

MATOS, M.S., CRISTINO, P.S., and ALMEIDA, T.F. Educação em saúde bucal do trabalhador. In: CHAVES, S.C.L. Política de saúde bucal no Brasil: teoria e prática [online]. Salvador: EDUFBA, 2016, pp. 273-295. ISBN 978-85-232-2029-7. https://doi.org/10.7476/9788523220297.0011.

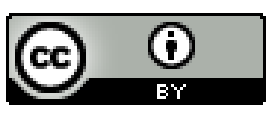

All the contents of this work, except where otherwise noted, is licensed under a Creative Commons Attribution 4.0 International license.

Todo o conteúdo deste trabalho, exceto quando houver ressalva, é publicado sob a licença Creative Commons Atribição 4.0. 


\title{
Educação em saúde bucal do trabalhador
}

\author{
Mariangela Silva de Matos \\ Patrícia Suguri Cristino \\ Tatiana Frederico de Almeida
}

\section{Apresentação}

Este capítulo faz uma abordagem dos aspectos históricos, políticos e conceituais do campo da educação em saúde, contextualizando-o para a realidade das práticas da saúde bucal do trabalhador. A busca da integralidade da atenção à saúde, a compreensão atual da multicausalidade das doenças e o desenvolvimento teórico e prático da promoção da saúde, contribuíram para mudanças nos modelos de atenção à saúde, com destaque para o desenvolvimento da vigilância da saúde, em contraponto ao modelo biomédico, centralizado no profissional de saúde, na cura da doença e nas causas biológicas e comportamentalistas das doenças. A vigilância da saúde, ao contrário, aponta para a necessidade do controle mais efetivo das causas e riscos, e não somente sobre os danos das doenças e agravos que atingem as populações. O movimento da promoção da saúde preconiza diferentes campos de ação em busca da qualidade de vida e bem-estar das populações. Dentre esses, destacam-se a capacitação da comunidade e o desenvolvimento de habilidades individuais e coletivas, os quais requerem a incorporação de ações educativas, sejam elas voltadas para o autocuidado ou para a educação popular. No processo de educação em saúde, é cada vez mais valorizada a participação ativa do educando nas estratégias de ensino-aprendizagem, possibilitando um processo dialógico e mais efetivo. 
Nesse contexto, insere-se a saúde bucal do trabalhador, o qual reconhece a importância da íntima relação entre ambiente de trabalho e condições bucais. As consequências do trabalho para a saúde bucal são reconhecidas cientificamente e os agravos bucais geram problemas relativos à qualidade de vida das pessoas, dor, dificuldade de mastigação, comprometimento estético e psicológico. No ambiente do trabalho, esses impactos podem ser responsáveis pela perda de produtividade devido ao absenteísmo, seja pelo incômodo da dor de origem odontológica ou pela alta frequência às consultas odontológicas. Desse modo, os fundamentos da educação em saúde consolidam-se como uma ferramenta indispensável para a organização dos serviços na área de saúde bucal do trabalhador, principalmente no âmbito dos programas preventivos.

\section{Abrindo o debate}

Abordar o tema educação em saúde bucal remete a um processo complexo que articula, numa perspectiva interdisciplinar, dois campos de saberes: o da educação e o da saúde. Na saúde, as diferentes formas de interpretar o processo saúde-doença ao longo da história definemas formas de intervenção sobre ele, incluindo a percepção da necessidade de se adotar, ou não, práticas de educação em saúde. Na educação, ocorrem importantes mudanças nas abordagens educativas, de modo que elas passam a valorizar, cada vez mais, a participação ativa do educando no processo ensino-aprendizagem.

Tal concepção começa a partir da década de 1970, sob forte influência da proposta pedagógica de Paulo Freire, a pedagogia libertadora, subsidiando importantes referenciais para as práticas de educação em saúde, na direção de um maior empoderamento (empowerment) da população, tanto em nível individual como coletivo. (ALVES, 2005)

Em se tratando das formas de intervenção sobre o processo saúde-doença, as políticas de saúde no Brasil pautaram-se, tradicionalmente, pelo modelo biomédico, com foco na cura e controle das doenças. A partir da evolução do conhecimento científico, avançando-se na compreensão da multicausalidade do processo saúde-doença, dos movimentos internacionais para nortear as políticas de saúde, do movimento da Reforma Sanitária no Brasil e da promulgação da Constituição Brasileira, com a criação e a busca de consolidação do Sistema Único de Saúde (SUS), impõe-se importantes mudanças nos modelos de atenção. Nesse contexto, a atenção primária passa a ser prioritária, valorizando-se as ações de promoção de saúde. 
Essas ações, de acordo com Paim (2003), aplicam-se, essencialmente, à melhoria das condições e estilos de vida de grupos populacionais específicos, apoiando-se amplamente em atividades de educação e comunicação em saúde e na formulação de políticas públicas saudáveis.

Avançando-se na concepção de modelos de atenção mais integrais, que orientem as intervenções sobre a saúde, constrói-se o conceito de vigilância da saúde, apontando para a necessidade do controle mais efetivo das causas eriscos, e não somente sobre os danos das doenças e agravos que atingem as populações. Deriva daí, a implantação da vigilância na área de saúde do trabalhador, levando-se em conta os ambientes de trabalho e os riscos ocupacionais. (PAIM, 2003)

Em relação à saúde, o trabalho pode trazer inúmeras consequências: destrutivas, benéficas, ou ambas, podendo operar de modo distinto conforme o momento histórico e com a organização dos trabalhadores, sendo um importante determinante do processo saúde-doença. A lógica da saúde pública, de prevenção de riscos e de promoção da saúde com a participação dos trabalhadores, constituindo o que se chama "saúde do trabalhador", efetivou-se no Brasil a partir do SUS, em 1988 (SANTANA; SILVA, 2012), sendo o fundamento das suas ações pautado em uma articulação multiprofissional, interdisciplinar e intersetorial. (BRASIL, 2002a)

O campo da saúde do trabalhador busca compreender as relações entre o trabalho e o processo saúde-doença, considerando-se os diversos riscos ambientais e organizacionais aos quais os trabalhadores estão expostos em seus processos de trabalho. (BRASIL, 2002a)

Assim, as ações de saúde do trabalhador devem ser incluídas formalmente na agenda da rede básica de atenção à saúde. Dessa forma, amplia-se a assistência já ofertada aos trabalhadores, na medida em que passa a olhálos como sujeitos a um adoecimento específico que exige estratégias - também específicas - de promoção, proteção e recuperação da saúde. (BRASIL, 2002a, p. 9)

A área de especialidade de odontologia do trabalho regulamentada pelas Resoluções n. ${ }^{\circ} 22$, de 27 de dezembro de 2001 , e n. ${ }^{\circ} 25$, de 28 de maio de 2002 , objetiva a busca permanente da compatibilidade entre a atividade laboral e a preservação da saúde bucal do trabalhador; e uma das suas competências é o planejamento e implantação de campanhas e programas de duração permanente para educação 
dos trabalhadores quanto a acidentes de trabalho, doenças ocupacionais e educação em saúde. (MAZZILLI, 2003)

Essas novas propostas de intervenção sobre a saúde passam a exigir ações intersetoriais e uma atuação multiprofissional e interdisciplinar, com a mobilização de outros campos de saberes, destacando-se a sociologia, a antropologia, a psicologia e a educação.

No campo da saúde bucal do trabalhador, as estratégias de educação em saúde devem ser conduzidas em duas perspectivas:

- Fomentar o autocuidado com ações voltadasao aprimoramento das habilidades individuais para prevenção e controle de problemas bucais e para a busca de cuidados profissionais;

- Fortalecer uma postura política reivindicadorade direitosque vão desde o acesso às ações e serviços de saúde até a criação deambientes de trabalho que permitamatividadeslaborais com o mínimo de risco.

Inúmeras pesquisas têm ressaltado os impactos das más condições bucais sobre a qualidade de vida das pessoas, expondo-as a dor, dificuldade de alimentação, comprometimento estético, desconforto psicológico, dentre outros. (MATOS; FLORIANO, 2011) Em se tratando da saúde bucal do trabalhador, esses impactos podem ser responsáveis pela perda de produtividadedevido ao absenteísmo, seja pela dor oupela alta frequência às consultas odontológicas para o tratamento dos danos.

Nesse contexto, a educação em saúde consolida-se como uma ferramenta indispensável para a organização dos serviços na área de saúde bucal do trabalhador, sobretudo na elaboração de programas preventivos, tendo em vista a qualidade de vida e a força de trabalho.

Na condução desse processo, Matos e Floriano (2011) consideram necessário:

- Compreender a multidimensionalidade do processo saúde-doença, identificando os determinantes sociais das doenças,o comportamento humano, valores e atitudes relacionados à saúde bucal como saberes fundamentais para as ações de promoção de saúde;

- Aceitar outras fontes de saberes (crenças, mitos, religião, senso comum) como conhecimentos válidos para melhor compreender as atitudes das pessoas relacionadas à saúde bucal; 
- Desenvolver práticas de educação e atenção em saúde pautadas na salutogênese, ou seja, em motivar as pessoas a buscar comportamentos saudáveis, não apenas com a perspectiva de evitarem doenças, mas também de alcançarem qualidade de vida e sensação de bem-estar;

- Aprofundar as evidências científicas na compreensão dos determinantes psicossociais do processo saúde-doença bucal e do impacto das condições bucais sobre a qualidade de vida das pessoas/população;

- Fortalecer a voz da comunidade frente às forças estruturantes que afetam a sua saúde.

\section{Interseções entre o processo saúde-doença, os modelos de atenção em saúde e as práticas de educação em saúde}

Para se entender a construção histórica da necessidade de ações educativas no campo de saúde, bem como as diferentes concepções e estratégias de educação adotadas, será feita uma abordagem de alguns marcos históricos que refletem as diferentes concepções do processo saúde-doença e a evolução dos modelos de atenção em saúde, buscando-se compreender, no cenário atual, a emergência da educação em saúde como ação prioritária nas políticas públicas de saúde.

\section{Concepções acerca do processo saúde-doença}

As civilizações antigas conviveram com o processo saúde-doença, compreendendo-o como fenômeno mágico-religioso,de modo que as formas de intervenção eram pautadas nos rituais de magia e feitiçaria, no uso de plantas medicinais e nas práticas de massagens, banhos e sangrias. (CARVALHO; MARTINS, 1998; OLIVEIRA; EGRY, 2000) É preciso considerar que muitas dessas práticas persistem até os dias de hoje, e que muitas delas foram desenvolvidas e ainda se configuram como tentativas de sobrevivência diante da exclusão social aos cuidados médicos, e não somente como resultantes de manifestações culturais ou religiosas. Daí, a necessidade de uma imersão cotidiana nos "saberes populares" em saúde.

A partir dos avanços científicos, a medicina moderna se expandiu no século XIX, marcada pelo desenvolvimento das ciências básicas como a anatomia, a fisiologia, a patologia e a microbiologia, bem como, pelo desenvolvimento das 
vacinas. O corpo humano era comparado a uma "máquina" e importava conhecer o homem de perto e entender o funcionamento de cada parte do seu corpo. Com base nesses conhecimentos, nasce o conceito biomédico, a partir do qual a determinação das doenças está fundamentalmente pautada em fatores externos ao corpo (microorganismos) ou têm origem em mudanças internas involuntárias como os desequilíbrios químicos ea predisposição genética. (CARVALHO; MARTINS, 1998; OLIVEIRA; EGRY, 2000) Nesse contexto a doença é percebida como um mau funcionamento de partes do corpo humano e a saúde é considerada como a ausência de sinais e sintomas. (OGDEN, 2004)

Como o discurso biologicista reduz o processo saúde-doença à dimensão individual, ele propaga que grande parte dos problemas de saúde bucal é decorrente da falta de higiene e, sendo assim, é possível resolvê-los a partir da mudança de comportamentos individuais. Diante dessa perspectiva, as práticas de educação em saúde são pautadas em discurso autoritário de prescrição de regras de higiene. (ALVES, 2005)

Tradicionalmente, os estudos sobre as condições de saúde bucal das populações humanas, abordavam aspectos biológicos e comportamentais, enfatizando os fatores individuais como determinantes das principais doenças bucais. (MATOS; FLORIANO, 2011) Esse referencial biomédico passa, então, a nortear os modos de intervenção ou modelos de atenção em saúde no mundo ocidental. No Brasil, o modelo de atenção hegemônico passa a ser o médicoassistencial privatista, o qual valoriza a atenção individual, voltado para uma demanda espontânea e focado na doença.

A exclusão provocada por esse modelo, no setor público, deu-se pelo fato do direito à assistência ter sido concedido somente aos trabalhadores contribuintes da Previdência Social, deixando à margem desse sistema o restante (maioria) da população. No setor privado, essa exclusão é intrínseca à barreira socioeconômica imposta aos que não podem pagar pelos serviços de saúde. Mas, tanto no setor público como no privado, esse modelo contém um traço excludente em comum: não consegue alcançar os indivíduos ou grupos populacionais para prevenção e controle de doenças ou mesmo, para a manutenção da saúde. Por essas e outras razões, esse modelo não consegue alterar significativamente os níveis de saúde da população. (PAIM, 2003)

Cabe ressaltar que esse modelo ainda é hegemônico não apenas em função do olhar biomédico, reforçado na própria formação acadêmico-científica, como também pela mercantilização da saúde, uma vez que o setor privado da saúde 
ainda se fortalece a partir dos procedimentos curativos. Aliás, a existência desses dois modelos não é coincidência histórica, eles se complementam: quanto mais doenças, maior o gasto em saúde; daí, o foco sobre a doença e não propriamente na defesa da vida.

No modelo biomédico, o referencial para a prevenção de doenças e educação em saúde é permeado por um discurso focado apenas no autocuidado e na culpabilização dos sujeitos que não seguem as regras prescritas, já que o contexto de vida é subestimado, tanto em razão do olhar biomédico como pelos traços neoliberais de sociedade, que colocam apenas no indivíduo a responsabilidade "ou culpa" pelo seu estado de saúde.

Entretanto, estudos passam a contestar o impacto das ações médicas nos níveis de saúde da população. Dentre estes, o Relatório Lalonde é considerado um marco histórico para a mudança de perspectivas quanto à determinação das doenças e os modos para o seu enfrentamento. O conceito de "campo da saúde", proposto por Lalonde, marca o surgimento das primeiras propostas alternativas de modelos de intervenções estatais na saúde das coletividades.

O Relatório Lalonde é fruto de um estudo realizado na década de 1970, no Canadá, o qual fundamentou o esquema quadridimensional de Lalonde. Este considera o estilo de vida, a biologia humana, o ambiente e os serviços de saúde, como os quatro determinantes do nível de saúde do povo canadense. Concluiu-se, a partir desse estudo, que a melhoria dos níveis de saúde no Canadá, dependeria muito mais de ações sobre o estilo de vida e o meio ambiente e de novos conhecimentos sobre a biologia humana do que da melhoria e expansão da rede de hospitais e outros serviços de saúde. Na dimensão estilo de vida, compreende-se que o comportamento do indivíduo em seu cotidiano, nos seus microambientes, é dependente ou influenciado em grande parte por fatores sociais, culturais e psicológicos, representando dimensão fundamental para a análise da sua saúde. (CHAVES, 1998)

A partir do lançamento dessa proposta de promoção de saúde, têm sido organizadas as conferências internacionais de saúde, com a proposta de discutir e nortear as políticas públicas de saúde nos diferentes países do mundo.

A I Conferência Internacional sobre Promoção da Saúdetem sido referida como uma das mais importantes iniciativas que delineou discussões voltadas para um novo movimento mundial da saúde pública e, a despeito da importância das diretrizes contidas em todos os documentos das demais conferências, a 
Carta de Ottawa foi um marco importante no estabelecimento do conceito de promoção de saúde.

De acordo com esse documento, promoção de saúde é conceituada como “[...] processo de capacitação da comunidade para atuar na melhoria da sua qualidade de vida e saúde, incluindo uma maior participação no controle desse processo [...]”. Assim, a promoção de saúde não é responsabilidade exclusiva do setor saúde, e vai além de um estilo de vida saudável. Nesse sentido, são considerados pré-requisitos para a saúde: paz, habitação, educação, alimentação, renda, ecossistema estável, recursos sustentáveis, justiça social e equidade. (BRASIL, 1996)

Para muitas doenças que afetam as populações, o instrumental científicotecnológico, por si só, não é suficiente para responder a alta complexidade que as envolve. Assim, emerge o desafio de se pensar a saúde sob a ótica do desenvolvimento e da condição humana, porque evidências têm mostrado que a saúde está muito mais relacionada com o modo de viver das pessoas do que com os fatores biológicos e genéticos. O sedentarismo, a alimentação não saudável, o consumo de álcool, tabaco e outras drogas, o frenesi da vida cotidiana, a competitividade, e o isolamento do homem nas cidades são condicionantes diretamente relacionados à produção das doenças modernas. (BRASIL, 2010)

A saúde passa a ser compreendida não apenas como a mera ausência de doenças, mas como resultante de um conjunto de fatores individuais e coletivos, sociais, econômicos, étnicos, religiosos, culturais, psicológicos, laborais, biológicos e ambientais. Desse modo, o cuidado com a saúde na atualidade não é mais compreendido como uma ação exclusiva dos profissionais da área de saúde (BRASIL, 1996), ou tampouco focado na atenção individual.

No século XX, com o desenvolvimento da noção de multicausalidade nas abordagens teóricas e conceituais sobre causa em saúde, incorporaram-se aspectos psicossociais na explicação do fenômeno saúde-doença em odontologia. (FREIRE, 2001; LACERDA, 2005; VASCONCELOS, 1999) Dessa forma, acredita-se que a estrutura, o contexto social e o modo de vida, entendidos como qualidade de vida, influenciam diretamente o nível individual de saúde bucal. (MATOS; FLORIANO, 2011)

Essas novas abordagens, ao longo do século XX, fizeram emergir a medicina psicossomática, e mais recentemente, a psicologia da saúde. A medicina psicossomática desenvolveu-se a partir de observações e estudos de Freud, nos quais ele afirmava que experiências e sentimentos reprimidos eram expressos sob 
a forma de um problema físico. A psicologia da saúde se sustenta no modelo biopsicossocial, desenvolvido por Engel no final da década de 1970 e, diferente do modelo biomédico, esse modelo representa uma busca de interação entre os determinantes biológicos, psicológicos e sociais, sugerindo que os seres humanos devem ser vistos como sistemas complexos e que a doença é causada por uma multiplicidade de fatores. De acordo com a psicologia da saúde, se a saúde e a doença são vistas como uma associação de fatores, o individuo já não é compreendido como uma vítima passiva da doença. Reconhecer o papel do comportamento na sua origem, como por exemplo, o ato de fumar, significa que os indivíduos podem ser corresponsáveis pelo seu estado de saúde e suas doenças. (OGDEN, 2004)

Para assumir essa corresponsabilidade, entretanto, é imprescindível que os sujeitos tenham acesso à informação e educação em saúde, bem como às condições financeiras, políticas e ambientais para o exercício desse papel.

\section{Educação em saúde nas políticas públicas}

Um dos pressupostos das Diretrizes da Política Nacional de Saúde Bucal é centrar a atuação na vigilância à saúde, incorporando práticas contínuas de avaliação e acompanhamento dos danos, riscos e determinantes do processo saúde-doença. Assim, o modelo assistencial centrado na doença e baseado no atendimento a quem procura evolui para um modelo de atenção integral à saúde, onde haja a incorporação progressiva de ações programáticas de promoção, proteção e recuperação. (BRASIL, 2004a)

A Carta de Ottawa propõe cinco campos de ação para se intervir na perspectiva da promoção de saúde: (1) implementação de políticas públicas saudáveis; (2) criação de ambientes saudáveis; (3) capacitação da comunidade; (4) desenvolvimento de habilidades individuaise coletivas; e (5) reorientação dos serviços de saúde. (BRASIL, 1996)

Tratando-se da criação de ambientes saudáveis, advoga-se que existem elos indissolúveis entre a população e o seu meio, e esses constituem a base para uma abordagem socioecológica da saúde. Ressalta-se que a maneira como a sociedade organiza o trabalho deveria ajudar a criar uma sociedade saudável e que as ações de promoção da saúde devem gerar condições de vida e de trabalho seguros, estimulantes, satisfatórios e agradáveis. (BRASIL, 1996)

Observa-se que dentre os cinco campos de ação, a capacitação da comunidade e o desenvolvimento de habilidades individuais e coletivas requerem a in- 
corporação de ações educativas, sejam elas voltadas para o autocuidado ou para a educação popular, tendo em vista a melhoria da qualidade de vida e saúde.

Tais ações referem-se a processos educativos e políticos que visam, tanto o empoderamento (empowerment) das comunidades no estabelecimento de prioridades, tomada de decisões, planejamento e implementação de estratégias com o objetivo de atingir um melhor nível de saúde, como a capacitação dos sujeitos para o desenvolvimento pessoal que os habilite para uma vida saudável. (BRASIL, 1996)

Desse modo, além da compreensão de educação em saúde como instrumento de orientação e motivação individual voltado para o autocuidado, o Relatório Final da $3^{\text {a }}$ Conferência Nacional de Saúde Bucal (BRASIL, 2004b), aponta que a educação em saúde deve ser considerada: (1) como meio para o reconhecimento da população de que a "saúde é direito de todos e dever do Estado"; (2) como instrumento de transformação social; (3) como instrumento de formação para uma nova cultura política de participação popular e de exercício de cidadania, de forma individual ou coletiva; e (4) como meio de fortalecimento do controle social do SUS.

Essa abordagem exige a mobilização da educação como instrumento capaz de proporcionar a formação do homem como agente de mudança; crítico, criativo, reflexivo; e capaz de assumir no conjunto das lutas sociais a sua condição de agente ativo de transformação da sociedade e de si próprio, na conquista de direitos e justiça social e na adoção de novas práticas de interlocução, participação e articulação das ações para além dos espaços institucionais. (BRASIL, 2004b)

Na perspectiva do autocuidado, a educação em saúde bucal é compreendida como "ações que objetivam a apropriação do conhecimento sobre o processo saúde-doença incluindo fatores de risco e de proteção à saúde bucal, assim como a possibilitar ao usuário mudar hábitos apoiando-o na conquista de sua autonomia". (BRASIL, 2004a, p. 9) Assim:

A educação em saúde bucal deve fornecer instrumentos para fortalecer a autonomia dos usuários no controle do processo saúde-doença e na condução de seus hábitos. Sua finalidade é difundir elementos, respeitando a cultura local, que possam contribuir com o empoderamento dos sujeitos coletivos, tornando-os capazes de autogerirem seus processos de saúdedoença, sua vida, com vistas à melhoria da sua qualidade de vida.(BRASIL, 2006, p. 25) 
Ao trabalhar a educação em saúde com indivíduos ou grupos comunitários não se deve esquecer a leitura que cada pessoa faz sobre si mesmo e sobre o mundo. É como sinaliza Paulo Freire (1996): o desrespeito à leitura de mundo feita pelo educando revela um comportamento antidemocrático do educador porque evidencia um desrespeito à inteligência das pessoas, as quais se constroem social e culturalmente. Além disso, desconsidera que as pessoas só se motivam para aprender novos conhecimentos e adotar atitudes que julgam úteis para a sua vida quando ambos estão de acordo com o seu jeito de ser e estar no mundo. Essa compreensão coloca o diálogo como elemento estruturante do processo educativo, uma vez que é impossível educar sem exercitar a escuta do outro, sem estabelecer uma ação comunicativa entre educador e educando, na qual ambos são agentes que, simultaneamente, ensinam e aprendem.

Nesse sentido, alguns aspectos importantes são recomendados ao se planejar a educação em saúde bucal (BRASIL, 2006, p. 26):

- $\quad$ Respeito à individualidade;

- Contextualização nas diversas realidades, incluindo as possibilidades de mudança;

- Respeito à cultura local;

- Respeito à linguagem popular para encaminhar uma construção conjunta da prática;

- Ética;

- $\quad$ Autopercepção de saúde bucal;

- Reflexão sanitária: o processo de educação em saúde deve capacitar os usuários para participar das decisões relativas à saúde;

- Uso de metodologias adequadas a cada situação e a cada grupo etário.

A Figura 1 traz uma visão esquemática das diretrizes apontadas pelas políticas públicas de saúde, as quais podem nortear as ações de educação em saúde no âmbito do SUS. Entretanto, considerando-se que o modelo hegemônico de educação é apenas focado no autocuidado, com práticas educativas autoritárias e prescritivas (ALVES, 2005), torna-se evidente o tamanho do desafio a ser enfrentado pelo SUS no sentido de legitimar as práticas de educação baseadas nessas diretrizes. 
Figura 1 - Diretrizes das políticas públicas de educação em saúde segundo os documentos oficiais

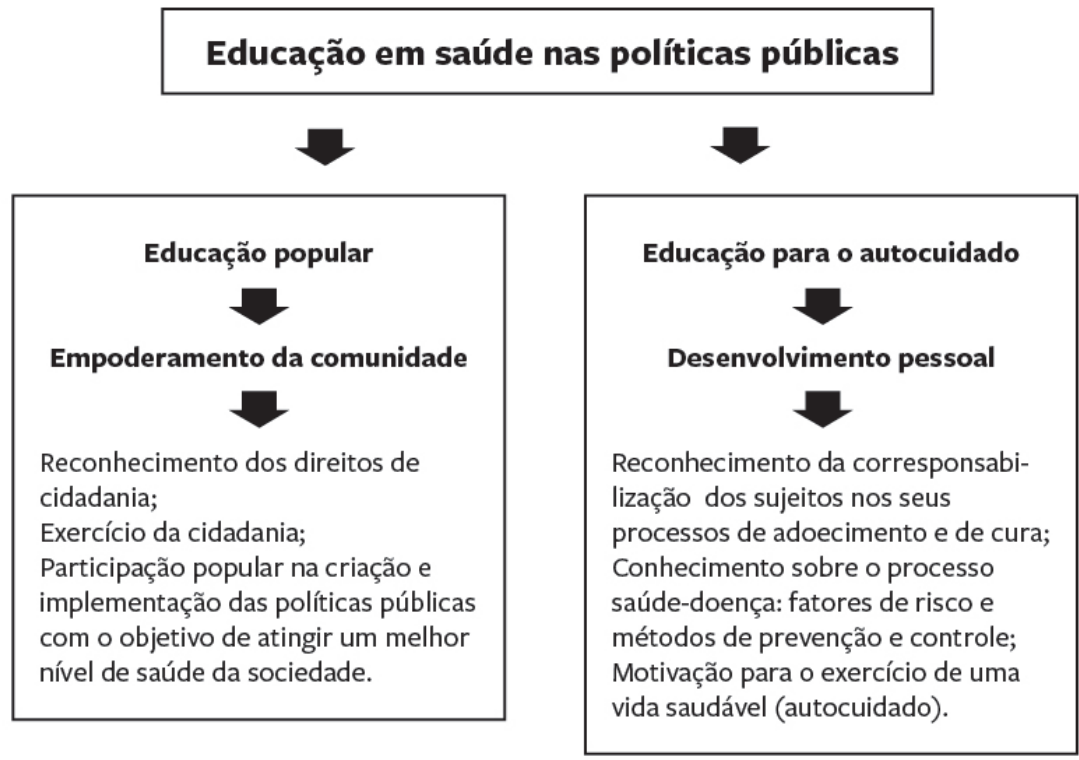

Fonte: Elaboração das autoras.

Observa-se que, no âmbito das políticas públicas, a educação em saúde vem sendo apontada como um importante instrumento para a consolidação do SUS. Os conceitos de educação incorporados no discurso oficial, bem como as diretrizes ou recomendações apontadas para nortear as práticas de educação em saúde, buscam superar o modelo tradicional de se pensar a educação e de se organizar as estratégias de intervenção, pautadas nas pedagogias tradicionais. A negação desse referencial vem dando lugar a propostas baseadas nas pedagogias críticas, as quais possibilitam o desenvolvimento de práticas educativas participativas que valorizam os saberes tácitos, a cultura e a autonomia dos sujeitos.

Entretanto, um dos grandes desafios para a consolidação dessa proposta se refere à compreensão que a grande maioria dos profissionais de saúde tem acerca do fazer educativo. Além da falta de valor atribuído a essa atividade, as concepções e práticas predominantes se baseiam nas pedagogias tradicionais. A educação permanente dos profissionais inseridos nos serviços de saúde e a ampla incorporação conceitual e prática dessa temática nos processos de 
formação profissional podem ser um caminho para a legitimação das políticas públicas de educação em saúde.

\section{Abordagens pedagógicas e práticas de educação em saúde}

Ainda que muitos de nós, ao realizar uma atividade educativa, não tenhamos consciência de que adotamos uma tendência pedagógica, para Bordernave (1983), todos os processos educativos têm por base uma determinada abordagem pedagógica. Ou seja, uma concepção de como se consegue fazer para que as pessoas aprendam alguma coisa e, a partir daí, possam fazer escolhas mais saudáveis, ainda que pese a força dos determinantes sociais em saúde.

Ao abordar os referenciais das práticas de educação em saúde para o Programa de Saúde da Família, Alves (2005), apesar de reconhecer a existência de modelos intermediários, apresenta dois modelos extremos: o tradicional e o hegemônico. O primeiro é focado na doença e no referencial biologicista, emprega estratégias educativas que valorizam as informações verticalizadas para ditar os comportamentos das pessoas, sendo o saber científico incorporado ao processo educativo com status de verdade. A autora argumenta que a principal crítica a esse modelo se refere à falta de consideração dos determinantes psicossociais e culturais dos comportamentos em saúde, perdendo-se de vista que as pessoas agem com as suas crenças, valores e representações do processo saúde-doença. Em oposição a esses referenciais, busca-se consolidar o modelo dialógico, no qual o usuário do serviço é reconhecido como um sujeito portador de um saber e que o papel da educação é reconhecer e transformar esses saberes, defendendo o protagonismo dos sujeitos e a sua responsabilidade no cuidado com a saúde. O diálogo é o instrumento pelo qual ocorre o intercâmbio entre os saberes técnico-científicos e os saberes populares, de modo a produzir-se um saber partilhado entre os profissionais de saúde e os usuários dos serviços, possibilitando a esses uma maior apropriação dos conhecimentos e a incorporação de novas atitudes favoráveis à saúde.

Assim, o planejamento de programas de educação em saúde requer uma discussão crítica dos referenciais pedagógicos tradicionais, buscando um modelo dialógico, no qual os educandos sejam abordados como sujeitos do processo educativo e não como meros receptores de conhecimentos. Para Freire (2005), o nosso papel não é falar ao povo sobre a nossa visão de mundo tentando impor a ele os nossos conteúdos que pouco têm a ver com os seus anseios, dúvidas, esperanças e temores. Conteúdos que, às vezes, aumentam os temores de uma 
consciência oprimida. O nosso papel é dialogar com ele sobre a sua e a nossa visão de mundo, entendendo que a ação educativa não pode prescindir do conhecimento crítico da realidade, da situação de mundo dos sujeitos porque, de outro modo, estaremos pregando no deserto.

Nessa perspectiva, estratégias que envolvem pedagogias críticas devem ser priorizadas, tais como: rodas de conversa, mesas demonstrativas interativas, oficinas de desenho, peças teatrais ou teatro de fantoches com textos produzidos a partir de um diagnóstico situacional dos grupos envolvidos, dentre outras. As rodas de conversa, inspiradas em Paulo Freire, permitem a horizontalidade na relação educador-educando e a circularidade da informação, de modo que, tanto os saberes populares quanto os saberes científicos, são importantes no processo de aprendizagem e na corresponsabilização com os cuidados necessários à saúde.

\section{Práticas de educação em saúde}

Os Cadernos de atenção básica apontam os conteúdos gerais a serem abordados nas ações coletivas de educação em saúde bucal. Destaca-se a seguir aqueles de interesse para os adultos: (1) conhecimento sobre as principais doenças bucais, como se manifestam e como se previnem; (2) a importância do autocuidado, da higiene bucal, da escovação com dentifrício fluoretado e o uso do fio dental; as orientações gerais sobre dieta; (4) a orientação para autoexame da boca; (5) a prevenção à exposição ao sol sem proteção; e, (6) a prevenção ao uso de álcool e fumo. (BRASIL, 2006)

Tais conteúdos devem ser pedagogicamente trabalhados, preferencialmente de forma integrada com outras áreas da saúde e podendo ser desenvolvidos na forma de debates, oficinas de saúde, vídeos, teatro, conversas em grupo, cartazes, folhetos e outros meios. (BRASIL, 2004a)

É importante compreender que, a despeito da importância de se trabalhar esses conteúdos, as ações de educação em saúde bucal não devem estar voltadas apenas para orientar as pessoas sobre as doenças e as diferentes formas de prevenção, mas também para estimulá-las a refletir sobre qual o valor que elas atribuem a sua saúde bucal, dentro do seu contexto de vida. Ajudá-las a refletir sobre os diferentes papéis que a boca exerce em suas vidas (alimentação, comunicação, estética facial, sexualidade, expressão de afetividade, por meio do beijo, e de felicidade, pelo sorriso) e que, em função disso, merece toda a nossa atenção e cuidado. 
As ações educativas não devem ser focadas apenas nas doenças, mas, também, nas possibilidades de prazer e bem-estar que uma boca saudável é capaz de nos proporcionar. Isso pode ser melhor compreendido a partir do pressuposto de que a motivação para o autocuidado é mais válida quando trabalhamos com estímulos que despertem pensamentos positivos (autoestima, bem-estar, prazer, aparência) do que quando optamos por despertar sentimentos negativos como o medo de contrair doenças e sofrer as suas sequelas. Segundo Martins (1998), os motivos que conduzem cada pessoa a cuidar dos seus dentes e da sua boca são internos ao indivíduo e dizem respeito ao seu desejo de ser socialmente aceito, de ser bonito e de cheirar bem.

Desse modo, para se planejar ações de educação em saúde bucal, é pertinente questionar: o que motiva as pessoas a viverem de modo mais saudável? Conhecer esses motivos pode apontar pistas importantes para o planejamento das ações educativas, uma vez que possibilita construir estratégias com base em motivações já explicitadas pelos educandos.

Sawazaki e Nakama (1997) buscaram identificar os motivos pelos quais a população procura o atendimento odontológico. Com essa finalidade, avaliaram 433 pais de crianças de o a 14 anos atendidos nas unidades básicas de saúde de Londrina, Santa Cantarina, os quais citaram como principais motivos: a estética (41\%), a saúde (29\%), evitar dor (15\%), preservar um hálito puro (9\%), higiene (4\%) e evitar gastos (2\%).

Ao pesquisar sobre as razões pelas quais 1.035 adolescentes de escolas públicas e privadas, na faixa etária de 10 a 19 anos, limpam os seus dentes, Matos e colaboradores (2009) registraram que 54,8\% das respostas estavam associadas à prevenção de cáries; 33,2\%, à intenção de ter um bom hálito; 19,7\%, de ter uma boa estética; e 3,3\%, para facilitar o convívio social.

Dessa forma, cada grupo com o qual se trabalha será sempre único, sendo necessário levantar suas crenças, demandas, valores, desejos, e não apenas as suas necessidades objetivas em saúde. Todas essas informações farão parte do substrato sobre o qual se planejará as ações educativas, uma vez que tais ações precisam ter/fazer sentido não apenas para o "educador”, mas sobretudo para os educandos. Para alguns grupos, "ter saúde bucal” pode estar mais atrelado aos fatores psicossociais das relações interpessoais, como ter um "hálito agradável" ou "sorriso bonito"; para outros; o "não ter dor" pode ser o mais impactante. Enfim, é preciso auscultar essas subjetividades, já que a educação não se dá apenas pela capacidade cognitiva, mas também pelos afetos, por aquilo que 
"nos afeta”. Há que se ressaltar aqui todo o cuidado ético que isso implica. A exploração do mundo das subjetividades como ponto de partida precisa ter assegurado o respeito aos sentimentos do outro, já que as perdas em saúde bucal têm muito a ver com vários tipos de perdas e barreiras interpostas pela vida. Em se tratando da população adulta, trabalhadora, muitas ausências podem se revelar na precariedade da saúde bucal.

Abordando os desafios da comunicação em saúde do trabalhador, Rangel (2004) questiona sobre como devemos fazer para que as informações trabalhadas ganhem para os educandos o sentido de compreensão que desejamos alcançar. De acordo com a autora, a comunicação é um fenômeno de expressão, interação e diálogo entre sujeitos, mediante a qual se produz os fenômenos da vida cotidiana. Desse modo, o primeiro passo é buscar compreender o sentido que o outro lhe deu, ou seja, como são interpretadas as orientações dadas aos trabalhadores em atividades educativas? Que significados eles atribuem à saúde, à doença, à prevenção, à promoção e às próprias ações educativas? Como eles reinterpretam e apreendem as orientações recebidas?

Compreender essa dinâmica da comunicação em saúde requer a avaliação continuada das ações educativas, buscando-se a melhoria dos resultados mediante uma maior proximidade entre as expectativas do educador e o que, de fato, os educandos conseguem atribuir em termos de significados e de valores, incorporando-os ao seu cotidiano.

Finalmente, é preciso considerar, ainda no universo das subjetividades, as raízes mais profundas da persistência dos fatores de risco. O fazer na educação em saúde, pensado numa dimensão mais humanizada, mais do que competente no sentido de esclarecer e informar, precisa adotar uma função de "apoio", para o qual se faz necessário o "vínculo". Nesse sentido, Campos (2003) defendeque o vínculo depende não somente da "disposição" dos profissionais de saúde, como também de conhecimentos sobre a inter-relação entre as pessoas, do modo como se dão os processos de "transferências", sendo também seu papel o "ajudar a se ajudar". E isso envolve identificar a rede de apoio possível em cada caso. No sentido da superação, comenta que "somente quando se sente apoiado é que se mostra seguro para arriscar alguns passos por conta própria". Depreende-se daí que educação em saúde seja um processo e não uma sucessão de "atividades educativas", na compreensão antiga das prescrições de bons comportamentos, que não chamam o "educador" para o enfrentamento, mas apenas o educando. 
No contexto da educação em saúde bucal do trabalhador, cabe perguntar: em que medida a equipe de saúde pode contar com (ou vir a construir) bases mais consistentes para se realizar essa função de "apoio" nas empresas? Será que nossos profissionais de saúde estão sensibilizados para esse papel? Ou seja, mais humanizado? Sem isso, talvez não faça muito sentido se pensar em educação em saúde no ambiente de trabalho, pois certamente uma série de condições emerge como necessária para a "criação dos ambientes saudáveis". Para muito além do universo das "informações", há que se pensar nas condições estruturais, físicas, mais tangíveis, até naquelas mais sutis, que passam mesmo pela qualidade do viver nesse ambiente onde o ser humano passa (ou gasta?) considerável parte da sua vida e onde talvez deposite sua maior parcela de energia.

\section{Proposições para educação em saúde}

Ao tratar a temática da educação em saúde, seja com grupos de graduação, de pós-graduação ou de educação permanente, é comum identificar-se como expectativa dos estudantes ou profissionais, o aprendizado de um modelo estruturado de prática, algo que seja facilmente reproduzido em suas atividades disciplinares ou em seus contextos de trabalho. Ainda que a apresentação de estratégias educativas ou relatos de experiências exitosas possam ser referências para o nosso "fazer educativo", cada contexto de prática tem as suas peculiaridades. Mesmo trabalhando com a abordagem por ciclo de vida, cada indivíduo ou cada grupo tem as suas particularidades (doenças mais prevalentes, fatores de risco específicos, crenças, valores, motivações). Além disso, cada um interpreta os seus problemas de saúde de forma diversa e os reinterpretam dando significados singulares às informações e orientações vinculadas às práticas educativas.

De acordo com Ferreira e colaboradores (2004), os programas de educação em saúde para adultos podem ser mais eficazes se forem considerados os seguintes aspectos:

- Envolvimento da equipe de saúde bucal no processo educativo;

- As atividades educativas devemconsiderar a determinação social dos problemas bucais e apresentar uma visão dinâmica do processo saúde-doença, buscando relacionar o autocuidado e a autonomia com a elevação da qualidade de vida; 
- Os educadores devem estar cientes da necessidade de motivação contínua dos educandos;

- As orientações para higiene bucal não devem ser pautadas na imposição de técnicas padronizadas, nem tampouco na prescrição de materiais dispendiosos para a higienebucal;

- O processo educativo deve ser continuado no decorrer do tratamento, e os profissionais podem conjugar a atenção individualizada às práticas em grupo;

- As metas a serem alcançadas devem ser realistas para que não causem frustração aos profissionais e sensação de incapacidade aos educandos;

- As atividades de educação para a saúde requerem do profissional a busca de estabelecimento de vínculo com os indivíduos, de modo a evitar a emergência de fatores que criem barreiras de comunicação;

- A linguagem deve ser clara e adequada a cada indivíduo ou grupo populacional.

Muito mais do que elaborar uma proposta padronizada para a organização de ações educativas na área de saúde, destaca-se a importância de educar os profissionais na perspectiva de que eles possam internalizar o processo educativo como um espaço de diálogo no qual os saberes científicos possam abrir espaços para os saberes da vida, uma vez que, no final das contas, são eles que ditam os comportamentos das pessoas em seu cotidiano.

Nesse sentido, o primeiro passo para o estabelecimento de programas de educação em saúde, numa perspectiva coletiva, é realizar um levantamento dos aspectos biopsicossociais e ambientais do grupo com o qual desejamos mediar o processo educativo. Segue-se a isso o planejamento das ações e a avaliação do processo, tendo em vista a sua melhoria, conforme demonstrado na Figura 2. 
Figura 2 - Planejamento de ações educativas

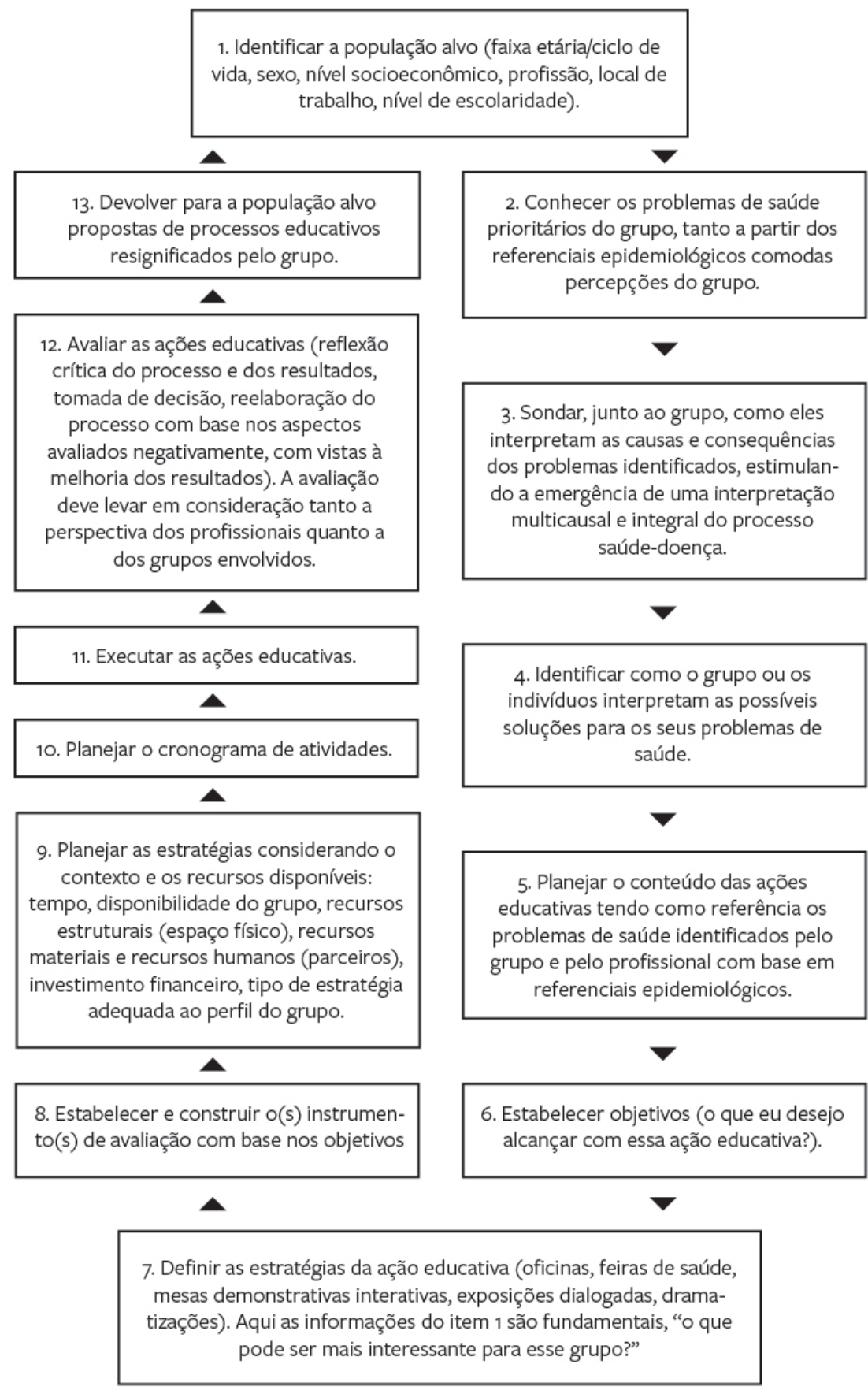

Fonte: Elaboração das autoras. 


\section{Estratégias de educação em saúde bucal do trabalhador}

$\mathrm{Na}$ área de saúde do trabalhador, busca-se avanços além da saúde do próprio trabalhador, visa-se integrá-lo com o ambiente, com o homem dignificado e satisfeito com a sua atividade, que tem vida dentro e fora do ambiente de trabalho e que almeja qualidade de vida. A partir desses pressupostos, as atividades de educação em saúde do trabalhador assumem fundamental relevância, devendo ir além dos programas de prevenção e campanhas para usos de equipamento de proteção individual com o intuito de atender a legislação vigente. Tornam-se essenciais as intervenções educativas que educam em um sentido mais amplo, que tenham um caráter humanitário, que colaborem para o empoderamento e autonomia em saúde, e em última instância produzam verdadeiramente bem-estar e valorização dos indivíduos. (OLIVEIRA, 2001) Vale lembrar que o desenvolvimento de programas de educação em saúde do trabalhador é atribuição de toda a equipe de saúde inserida nos serviços públicos da atenção básica no país. (BRASIL, 2002a)

As intervenções educativas em saúde bucal do trabalhador devem ser planejadas de acordo com os princípios da saúde do trabalhador. Ademais, deve-se considerar que o grupo populacional que exerce alguma atividade laboral, além de ser exposto aos fatores de risco comuns para os problemas bucais na população em geral, como a placa bacteriana e a higiene bucal inadequada, também está em contato direta ou indiretamente com outros fatores de risco ocupacionais, como a exposição a substâncias químicas, agentes físicos, mecânicos e radiações que aumentam ainda mais a probabilidade da ocorrência de lesões nos tecidos bucais. Assim, os trabalhadores devem ser olhados como indivíduos que estão sujeitos a um adoecimento específico e que exigem estratégias específicas de promoção, proteção e recuperação da saúde. (BRASIL, 2002a)

Essas estratégias devem ser planejadas e executadas com foco nos riscos ocupacionais específicos das atividades laborais. Assim em uma mostra de saúde cujo público alvo é constituído por salva-vidas, a abordagem do câncer de boca é pertinente, já que a radiação solar aos quais eles são expostos está associada com o surgimento de neoplasias, especialmente de lábio. Para essa intervenção, podem ser realizadas mesas demonstrativas, orientação sobre o autoexame bucal e também exames bucais a fim de se realizar uma triagem de indivíduos que possam apresentar esse problema bucal que pode levar à morte.

As estratégias de educação em saúde bucal, sempre que possível, devem possuir um caráter interdisciplinar, por meio das quais profissionais de dife- 
rentes áreas da saúde podem abordar os mais diversos temas, como: hipertensão, diabetes, acuidade visual, cárie dental, doença periodontal, câncer bucal, dentre outros.

\section{Considerações finais}

Os educadores em saúde devem considerar a realidade do indivíduo/comunidade, utilizando o diálogo como ponto de partida. Isso exige o abandono de posturas autoritárias, tanto profissionais como pessoais. Devem, ainda, considerar que, por trás de uma boca da qual ele está falando, existe uma pessoa, com uma história de vida, com um perfil psicológico e com uma inserção socioeconômico-cultural. Portanto, não basta informar e cobrar mudanças comportamentais apenas a partir das informações dadas.

O aprendizado é significativo quando o educando é respeitado em seus conhecimentos, percepções, crenças, valores, ideias, esperanças, expectativas e sentimentos. Por mais que consideremos os conhecimentos científicos importantes para a compreensão do processo saúde-doença e dos métodos de prevenção, as pessoas, em seu cotidiano, agem de acordo com as suas vivências, construídas individual e socialmente. Portanto, o grande desafio para os educadores em saúde é reconhecer no processo educativo a necessária associação entre os saberes científicos e os saberes e vivências populares.

\section{Referências}

ALVES, V. S. Um modelo de educação em saúde para o Programa Saúde da Família: pela integralidade da atenção e reorientação do modelo assistencial. Interface - Comuncação, Saúde, Educação, Botucatu, v. 1, n. 16, p. 39-52, set. 2004/fev. 2005.

ARAÚJO, M. E.; MARCUCCI, G. Estudo da prevalência das manifestações bucais decorrentes de agentes químicos no processo de galvanoplastia: sua importância para área de saúde bucal do trabalhador. Odontologia e Sociedade. v. 2, n. 1/2, p. 20-25, set./dez. 2000.

BORDENAVE, J. E. D. Alguns fatores pedagógicos. Revista Interamericana de Educação de Adultos, v. 3, n. 1-20, 1983. (Texto traduzido e adaptado do artigo 'La transferencia de tecnologia apropriada al pequeño agricultor’ por Maria Thereza Grandi, OPAS, Brasília, 1983)

BRASIL. Ministério da Saúde.Carta de Otawa, Declaração de Adelaide, Sundsvall e Santa Fé de Bogotá. Trad. por Luis Eduardo Fonseca. Brasília, 1996. 
BRASIL. Ministério da Saúde. Cadernos de Atenção Básica. Programa Saúde da Família. Saúde do Trabalhador. n. 5. Brasília, 2002. 63p. Disponível em: <www.saude.gov.br>. Acesso em: 14 set. 2011.

BRASIL. Ministério da Saúde. Diretrizes da Política Nacional de Saúde Bucal. Brasília, 2004a. Disponível em: < http://bvsms.saude.gov.br/bvs/publicacoes/politica_nacional_brasil_ sorridente.pdf >. Acesso em: 27 ago. 2004.

BRASIL. Ministério da Saúde. Relatório Final da $3^{a}$ Conferência Nacional de Saúde Bucal: acesso e qualidade superando a exclusão social. Brasilia, 29/07 a 01/08, 2004b. Disponível em: < http://bvsms.saude.gov.br/bvs/publicacoes/3_conferencia_nacional_saude_bucal_ relatorio_final.pdf >. Acesso em: 27 nov.2004.

BRASIL.Ministério da Saúde. Cadernos de Atenção Básica. Programa Saúde da Família. n.17. Brasília, 2006. 92p. Disponível em: <www.saude.gov.br>. Acesso em: 14 set. 2011.

BRASIL. Ministério da Saúde. Política Nacional de Promoção da Saúde.. Brasília, DF, 2010. Disponível em: <http://bvsms.saude.gov.br/bvs/publicacoes/politica_nacional_promocao_ saude_3ed.pdf $>$. Acesso em: 9 jun. 2016.

CAMPOS, G. W. S. Saúde paideia. São Paulo: HUCITEC, 2003.

CARVALHO, C. L.; MARTINS, E. M. O. O significado da saúde e da doença nas sociedades: guia curricular para formação do atendente de consultório dentário para atuar na Rede Básica do SUS: área I e II, Brasília: Ministério da Saúde, 1998. p. 91 - 102.

CHAVES, M. Complexidade e transdisciplinaridade: uma abordagem multidimensional do setor saúde. Maio, 1998. Disponível em: <http://www.uesc.br/cpa/artigos/ transdisciplinaridade.pdf $>$ Acesso em: 18 ago.2004.

FERREIRA, R. I. et al.Dental health education for adult patients: report of an experience. Revista de Odontologia da UNESP. Marília, v. 33, n. 3, p.149-56, 2004.

FREIRE, M.C.M. Fatores psicossociais, cárie dentária e comportamentos em saúde bucal. Revista ABOPREV, v. 4, n.1, p. 21-28, jan./jun, 2001.

FREIRE, P. Pedagogia da autonomia:saberes necessários à prática educativa. 25. ed. São Paulo: Paz e Terra 1996.

FREIRE, P. Pedagogia dooprimido. 41. ed. Rio de Janeiro: Paz e Terra, 2005.

LACERDA, J.T. Impacto da saúde bucal na qualidade de vida.2005. 173 f. Tese (Doutorado em Medicina Preventiva)- Universidade de São Paulo, São Paulo. 2005.

MARTINS, E. M. Educação em saúde bucal: o desafio de uma prática. Caderno de Odontologia, v. 1, n. 2, p. 30-40, jan./jun. 1998.

MATOS, M. S. et al. Hábitos de higiene bucal e dieta de adolescentes de escolas públicas e privadas em Salvador, Bahia. Revista Brasileira de Ciências da Saúde, João Pesso, v.13, n. 2, p. 7-14, 2009.

MATOS, M. S; FLORIANO, F. R. Saúde bucal e qualidade de vida. PRO-ODONTO. Prevenção. Ciclo 4, módulo 3, p. 45-92, Rio de Janeiro, 2011. 
MAZZILLI, L. E. N. Odontologia do trabalho. São Paulo: Ed. Santos, 2003.

OGDEN, J. Psicologia da saúde. 2. ed. Lisboa: Climepsi Editores, 2004.

OLIVEIRA, M. A. C.; EGRY, E. Y. A historicidade das teorias interpretativas do processo saúde-doença. Revista da Escola de Enfermagem da USP, São Paulo, v. 34, n. 1, p. 9-15, mar. 2000 .

OLIVEIRA, SG. Proteção jurídica à saúde do trabalhador. 3. ed. rev., ampl. e atual. São Paulo: LTr, 2001.

PAIM, J. S. Modelos de atenção e vigilância da Saúde. IN: ROUQUAYROL, M. Z.;

In: ALMEIDA FILHO, N. Epidemiologia e Saúde. 6. ed. Rio de Janeiro: MEDSI, 2003. p. 567586. Capítulo 19.

RANGEL, M. L. Educação e comunicação em segurança e saúde do trabalhador. Módulo 6. Curso de Especialização a Distância em Saúde e Segurança no Trabalho. Programa de Educação Continuada em Saúde e Segurança no Trabalho. ISC-UFBA/ UNISESI. 2005

SAWAZAKI, I; NAKAMA L. Educação para a saúde bucal: trabalho em equipe e aspectos psicossoaiais. Semina. v. 8, n. esp., p. 15-24, 1997.

SANTANA. V. S.; SILVA, J. M. Epidemiologia e saúde do trabalhador no Brasil. In: ALMEIDA FILHO, N.; BARRETO, M. L. Epidemiologia e saúde. Rio de Janeiro: Guanabara Koogan, 2012.

VASCONCELOS, E. M. A priorização da família nas políticas de saúde. Saúde em Debate. v. 23, n. 53, p. 6-19, 1999. 